\title{
National Education Policy 2021-Challenges and Opportunities of the Education System
}

\author{
Naraddya Rnder \\ Department of Political Science, Osmania University, Hyderabad, India \\ naraddya_r@gmail.com
}

\begin{abstract}
The National Policy on Education, 1986 and the Programme of Action, 1992 envisaged free and compulsory education of satisfactory quality to all children below 14 years. While the act has ensured education to all, the prevailing challenges of the education system remained thereby hindering the growth of Indian education system to the global level. The recent education policy by the Government of India is the first in 34 years replacing the National Policy of Education of 1986. The new policy introduced many reforms in the Indian education system beginning with reformation at central level and renaming the Ministry of Human Resource and Development to Ministry of Education. The NEP proposes revision and revamping of education structure, including its regulation and governance, to create a new system aligning with the aspirational goals of $21^{\text {st }}$ century education. The NEP proposes sweeping changes including opening up of Indian higher education to foreign universities, dismantling of the Universities Grants Commission and the All India Council for Technical Education. The policy, while focusing on various facets of education, also tries to bridge the gap between education and technology. One of the key highlights of NEP 2020 is the decision to make mother tongue or regional language as the medium of instruction up to Class 5. Further, the policy emphasizes the need for formative assessments and encouraging peer review system of assessment by creating National Assessment Centre and developing a system such as Performance Assessment Review and Analysis of Knowledge for Holistic Development for monitoring the achievement of learning outcomes and guide the boards of education to make learning more contemporary and suited to future needs. The biggest highlights of the NEP 2020 are that there would be single regulation for higher education institutions with setting up of Higher Education Commission of India that will eventually replace the existing regulatory bodies like the UGC or AICTE. The long - term plan of the policy is to do away with the current system of colleges affiliated to universities and numerous tiny colleges that are pedagogically unviable and financially costly would be merged with larger HEIs. The NEP 2020 aims to address various gaps existing in the education system of India and through this policy, India is expected to achieve sustainable development goal of 2030 by ensuring inclusive and equitable quality education.
\end{abstract}

Keywords: National Education Policy 2020, Higher Education Institutions, Curriculum

\section{Introduction}

Education is a continuous process which deals with over growing man in ever growing society. The education system needs to make students as learners, innovators, scholars, researchers and trainers. Despite a strong and constant economic growth during past couple of decades, India still faces socio - economic challenges and improving education is the only way forward to address the challenges and boost country's economic growth. However, decoding the education system in India to address the prevailing challenges is a herculean task as India is a nation of India is a nation of 28 States and 08 Union Territories. Since, the states have their own elected governments and school education being a state subject as per the constitution; the states have complete authority on deciding policies and implementing them (Anderson and Lightfoot, 2019) ${ }^{1}$. While educational policies are designed at central level by the Government of India, the state governments have freedom in implementing these policies. National Council for Educational Research and Training (NCERT) is the national organization that develops policies and programmes, designs curriculum framework and guidelines that are followed by the SCERTs of respective states. The National Policy on Education, 1986 and the Programme of Action, 1992 envisaged free and compulsory education of satisfactory quality to all children below 14 years. The educational

${ }^{1}$ Anderson, $\mathrm{J}$ and Lightfoot, A., The school education system in India: An Overview, British Council of India, New Delhi, July 2019, pp. 1-52. policies were not constitutionally safeguarded until Right to Education Act (RTD) was enacted on $04^{\text {th }}$ August 2009 and enshrined within the Article 21 (a) of the Indian Constitution making it a fundamental right of every citizen (Gautam et al, 2016) ${ }^{2}$. While the act has ensured education to all, the prevailing challenges of the education system remained thereby hindering the growth of Indian education system to the global level. With an aim to create an educational environment that matches global standards, the Government of India constituted a Committee for Draft National Educational Policy in 2019 chaired by Dr. K. Kasturirangan, Former Chairman of Indian Space Research Organization (KPMG, 2020) ${ }^{3}$. The Union Cabinet approved the policy paper designed by the Committee and National Educational Policy 2020 came into effect on $29^{\text {th }}$ July 2020. The new policy aims for public investment and aims to reach $6 \%$ of the GDP in educational sector from the existing $4.5 \%$. In this paper, the analysis of policy is carried out in order to assess the impact on the existing educational system in the states, in terms of social and political challenges, and how would it impact the students in current and future scenario.

\section{National Educational Policy 2020}

The recent education policy by the Government of India is the first in 34 years replacing the National Policy of

${ }^{2}$ Gautam, M, Singh, S., Fartyal, G., Tiwari, A. \& Arya, Kuldeep. Education System in Modern India. International Journal of Scientific Research And Education. 04 (01), 2016, pp. 4876 4879.

3 KPMG, Impact of National Education Policy 2020 and Opportunities and Stakeholders, 2020, pp 3 -28 
Education of 1986. The new policy introduced many reforms in the Indian education system beginning with reformation at central level and renaming the Ministry of Human Resource and Development to Ministry of Education (KPMG, 2020) ${ }^{4}$. The new ministry is dedicated towards strengthening the education system. The policy envisions offering a new structure to the education system in the country. The new education system entails education from pre - school / anganwadi to higher education. The NEP proposes revision and revamping of education structure, including its regulation and governance, to create a new system aligning with the aspirational goals of $21^{\text {st }}$ century education. The present $10+2$ structure is reformed into $5+3+3+4$ design corresponding to age groups $3-8$ years (foundational stage), 8 - 11 years (preparatory), 11 - 14 years (middle) and 14 - 18 years (secondary). This policy brings pre - school education under the purview of formal schooling. The policy aims to achieve $100 \%$ Gross Enrolment Ratio in school education by 2030 by bridging social gaps in access, participation and learning outcomes in school education (Singh, 2020). ${ }^{5}$

\section{Institutional changes to the educational system}

The NEP proposes sweeping changes including opening up of Indian higher education to foreign universities, dismantling of the Universities Grants Commission and the All India Council for Technical Education. One of the paradigmatic shifts is the setting up of the Higher Education Commission of India (HECI) that will act as a single regulator and several functions including accreditation, funding and academic standard setting. Further, structural changes include creation of National Curriculum Framework that will implement changes in curriculum, pedagogy and other content needs (KPMG, 2020) ${ }^{6}$. The policy, while focusing on various facets of education, also tries to bridge the gap between education and technology. The current pandemic circumstances has paved way for virtual learning replacing the traditional method of schooling compelling the teachers and students to re - imagine learning and teaching techniques. Under this policy, the National Educational Technology Forum will be established which shall operate as a platform for free exchange of ideas on the use of technology to enhance learning, assessment planning and administration for school and higher education (Prasad, 2020) 7 . Further, the policy emphasizes the need for formative assessments and encouraging peer review system of assessment by creating National Assessment Centre and developing a system such as Performance Assessment Review and Analysis of Knowledge for Holistic Development (PARAKH) for monitoring the achievement of learning outcomes and guide the boards of education to make learning more contemporary and suited to future needs $\left(\right.$ KPMG, 2020) ${ }^{8}$. The NEP 2020 envisages paradigm shift in education system by complete overhaul of existing institutions and creating a new institutional design that

\footnotetext{
${ }^{4}$ Ibid, p.4

Singh, B. Opinion: The language conundrum of National Education Policy 2020, ET Government, Economic Times, October 9, 2020.

${ }^{6}$ Op Cit, KPMG, 2020, p. 10-12

7 Prasad, H., National Education Policy 2020: Major Impact on Your Child's Curriculum \& Future, Univariety, August 3, 2020.

${ }^{8}$ Op Cit, KPMG, 2020, p. 10-12
}

focuses on students, teachers, school and college administration, curriculum and pedagogy and universal grading system that is compatible with the global educating system.

\section{School Curriculum and Pedagogy}

Under the National Education Policy 2020, the $10+2$ structure of school curriculum will be replaced by $5+3+3$ +4 with 12 years of schooling with three years of pre schooling. The policy lays emphasis on four key areas of reforms i. e. curricular changes to build strong foundational skills, improving quality of learning across all levels of education, shift in the ways of assessment and need for systemic transformation (NEP, 2020) ${ }^{9}$. The policy stresses on creating a national curricular and pedagogical framework which is competency based, inclusive, and innovative and focuses on comprehensive development of children. The curriculum shall focus on holistic development of learners by equipping them with $21^{\text {st }}$ century skills, mathematical and scientific temper. The emphasis is also on reduction in syllabus to enhance essential learning and critical thinking (KPMG, 2020) ${ }^{10}$. It is further noted that vocational education will be imbibed into school curriculum from Class 6 onwards and every children will learn at least one vocational skill and to expose 50 percent of the learners in school and higher education to vocational skills by 2025 . Further, in higher education, students can opt for any subjects among various streams such as Arts, Humanities, Sciences, Sports and Vocational subjects (Prasad, 2020) ${ }^{11}$. The main focus is on experiential learning by giving assignments, projects, real time learning experience, interactions and improved skills. The policy envisages a sweeping structural re - design of the curriculum and to deliver this effectively, there is dire need of trained teachers who understand pedagogical needs to make smooth transition to the new education system. Further, the system needs to shift the focus from teacher - centric to student centric learning to foster collaborative skills, critical thinking, problem solving and decision making abilities among children. As the policy entails bringing back nearly 250 million students back to school by 2030, this would require nearly 7 million additional teachers to handle this kind of student population (Ralhan, 2020) ${ }^{12}$.

\section{Examination and Assessment}

The policy does not revisits the concept of 'no detention policy' which guaranteed promotion through Class 1 to 8 to all children, irrespective of their skills and readiness to move to other class (Joshi, 2020) ${ }^{13}$. Under NEP 2020, the board exams for Class 10 and 12 will be made easier and the exams will test core capacities, competencies rather than months of coaching or memorization. Further, the progress card of all students for school - based assessment will be redesigned to a 360 degree multidimensional report card that will show the progress and uniqueness of each student in the

\footnotetext{
${ }^{9}$ National Education Policy 2020, Ministry of Human Resources and Development, Government of India, p.7.

${ }^{10}$ Op Cit, $K P M G$, 2020, p. 6-8.

${ }^{11}$ Op Cit, Prasad 'Univariety', August 3, 2020.

12 Ralhan, B.D. 'Challenges in implementing the National Education Policy 2020', Entrepreneur India. October 16, 2020.

13 Joshi, N. 'No Detention - Why did a popular policy got scrapped?', IDR, April 10,
} 
cognitive, affective and psychomotor domain (NEP, 2020)

14. The primary purpose of changing the assessment system is to promote continuous tracking of learning outcomes, which, however, would require schools and teachers to use innovative evaluation approaches and assignments. In India, 75 percent of schools are government aided and remaining are private schools, among which, nearly 80 percent are budget schools (Dr. Maram, 2020) ${ }^{15}$. Hence, deploying a continuous assessment framework is a challenging task.

\section{Debate on Linguistics and Culture}

One of the key highlights of NEP 2020 is the decision to make mother tongue or regional language as the medium of instruction up to Class 5. While this may create a long term impact in nation building, it also ensures transition from mother tongue or regional language to foreign language and helps inculcate human values and emotions and stay connected to their own social and cultural fabric (Narayan, 2020) ${ }^{16}$. It is observed that politics over language or culture is significant in India while regional languages debating over use of Hindi or English in their schools as medium of teaching. The education policy promotes three - language formula with two of the languages being native to India and these languages will be the choice of states, regions and chosen by the students. The policy focuses on multilinguism with great cognitive benefit to young children. Under this policy, the Kendra Vidyalayas and Navodaya Vidyalayas will implement the language policy and such schools will implement three language policies within the purview of states/ region. However, implementing this policy seems to be a might challenge as India is a nation of several languages, approximately 270 mother tongues as per Census 2011, and classrooms might have children with more than one spoken language (Singh, 2020) ${ }^{17}$. Nevertheless, observers argue that how imposing Hindi language on regional states, specifically southern states, does would achieve anything to the policymakers other than English and mother tongue. According to India Skill Report by CII and Wheebox, English is among the top 3 skills employers look for and three southern states of Karnataka, Tamil Nadu and Telangana attract IT companies and contribute IT exports as they have a large percent of the English speaking population, among other factors (Singh, 2020) ${ }^{18}$. Further, the intervention will require hiring of teachers and high quality learning resources in many different languages, which will be challenging to develop. It is important to note that higher education institutions have English as the medium of education. Therefore, it is difficult to understand what the students would achieve by learning the third language which would anyway be foreign, when the mother tongue would ensure social connectivity and English would allow global learning.

\section{Higher Education}

The biggest highlights of the NEP 2020 are that there would be single regulation for higher education institutions with

\footnotetext{
${ }^{14}$ Op Cit, NEP 2020, pp. 11-20.

15 Dr. Maram, H.K. 'National Education Policy 2020 - Execution Challenges', Education Post, September 5, 2020.

${ }^{16}$ Narayan, B. 'NEP 2020: Teaching students in mother tongue will help inculcate human values in them', Outlook, July 31, 2020.

${ }^{17}$ Op Cit, Singh, 2020.

${ }^{18}$ Op Cit, Singh, 2020
}

setting up of Higher Education Commission of India that will eventually replace the existing regulatory bodies like the UGC or AICTE. The long - term plan of the policy is to do away with the current system of colleges affiliated to universities and numerous tiny colleges that are pedagogically unviable and financially costly would be merged with larger HEIs (KPMG, 2020) ${ }^{19}$. The policy aims to instill greater institutional autonomy through independent Board of Governor and all standalone professional educational institutions to become multidisciplinary by 2030. All the HEIs would convert itself into multidisciplinary institutions with minimum student strength of 3000 by 2030 (Chopra, 2020) ${ }^{20}$. The policy promotes flexibility in choice of subjects and there will be no rigid separations between arts and sciences, curricular and extracurricular activities, and vocational and academic streams.

The HEIs are restructured into three tier institutional architecture i.e. Tier 1 - Research Universities, Tier 2 Teaching Universities and Tier 3 - Autonomous Colleges (KPMG, 2020) ${ }^{21}$. This system established by 1960 California Master Plan for higher education resulted in university system being segregated into three different categories to achieve excellence, increase access to students and reduce educational costs. It is important to note that California Master Plan designed in 1960 to ensure college access, promote excellence in research and skilled workforce (Finney et al, 2014) ${ }^{22}$. The policy which is 60 years old is adopted by NEP 2020 distinguished HEIs into three tiers to achieve the goals by $2030-2035$. What would be efficacy of this policy after 15 years with changing socio - economic dynamics in the world and how would this system ensure that the HEIs would constantly produce skilled work force competing with global labour demand. Many institutions will be set up to regulate institutions, provide accreditation to HEIs, develop learning outcomes for higher education programmes and provide funding to HEIs based on transparent criteria. This policy would not disturb the existing alliance with foreign universities and the transition of students to UK HEIs will be unaffected (British Council, 2020) ${ }^{23}$.

The NEP has also paved way for foreign universities to set up campuses in India through institutional collaboration and exchange of students and faculty. However, there is no evidence that this policy would excite the reputed foreign universities to come looking for entry opportunities as some of the top universities including Yale, Cambridge, Stanford, Bristol and others had shown no interest in the Indian market during UPA - II regime (Chopra, 2020) ${ }^{24}$. While the policy

\footnotetext{
${ }^{19}$ Op Cit, KPMG, 2020, pp. 12-15

${ }^{20}$ Chopra, R. 'Explained: Here are the key takeaways of India's National Education Policy', The Indian Express, November 19 , 2020

${ }^{21}$ Op Cit, KPMG, 2020, pp 10-15.

${ }^{22}$ Finney, J.E., Riso, C., Orosz, K. and Boland, W.C. 'From Master Plan to Mediocrity: Higher Education Performance \& Policy in California', Institute for Research on Higher Education, University of Pennsylvania, 2014, pp. 2-27.

${ }^{23}$ British Council, 'India's New Education Policy 2020: Highlights and Opportunities', International Education Services, British Council, August 24, 2020.

${ }^{24}$ Op Cit, Chopra, 2020.
} 
has been introduced, the government has its job cut out to facilitate establishment of reputed foreign universities in India.

\section{Conclusion}

The NEP 2020 aims to address various gaps existing in the education system of India and through this policy, India is expected to achieve sustainable development goal of 2030 by ensuring inclusive and equitable quality education. However, the policy needs immediate collaboration between state and central authorities to establish newly proposed bodies, define rules and regulations for schools and establish convergence of various schemes and acts with NEP 2020. In order to develop skills among teachers to address manpower shortfalls, training programmes should be designed to train master faculty members. As the policy aims to invest $6 \%$ of the GDP through public and private investment, it is suggested that there should be an ongoing collaboration with the industry partners in block chain, AI and predictive analytics industry with industry participation in research, delivering short - term skill certificates and co - partnering in creation of online universities. There is an opportunity of expansion in HEIs through increased academic and administrative autonomy for quality enhancement. Further, there is scope to develop tailored vocational programmes with HEIs which can be employment oriented and at affordable prices. More importantly, the government would require to earmark funds for develop textbooks, learning materials, etc. in different languages. However, it is imperative to define the list of languages instead of creating chaos in the system as it will require complete infrastructure overhaul, hiring of language teacher in each school and adjusting the curriculum as per the mother tongue or regional language. While, NEP 2020 provides opportunities in revamping the educational system to match the international standards, it requires lot of infrastructure and institutional restructuring apart from support from states to implement the policy successfully.

\section{References}

[1] Anderson, J and Lightfoot, A., The school education system in India: An Overview, British Council of India, New Delhi, July 2019.

[2] British Council, 'India's New Education Policy 2020: Highlights and Opportunities', International Education Services, British Council, August 24, 2020.

[3] Chopra, R. 'Explained: Here are the key takeaways of India's National Education Policy', The Indian Express, November 19, 2020.

[4] Dr. Maram, H. K. 'National Education Policy 2020 Execution Challenges', Education Post, September 5, 2020.

[5] Finney, J. E., Riso, C., Orosz, K. and Boland, W. C. 'From Master Plan to Mediocrity: Higher Education Performance \& Policy in California', Institute for Research on Higher Education, University of Pennsylvania, 2014, pp.2 - 27.

[6] Gautam, M, Singh, S., Fartyal, G., Tiwari, A. \& Arya, Kuldeep. Education System in Modern India. International Journal of Scientific Research And Education.04 (01), 2016, pp.4876 - 4879.
[7] Joshi, N. 'No Detention - Why did a popular policy got scrapped?', IDR, April 10,

[8] KPMG, Impact of National Education Policy 2020 and Opportunities and Stakeholders, 2020, pp 3 - 28

[9] Narayan, B. 'NEP 2020: Teaching students in mother tongue will help inculcate human values in them', Outlook, July 31, 2020.

[10] National Education Policy 2020, Ministry of Human Resources and Development, Government of India, p.7.

[11] Prasad, H., National Education Policy 2020: Major Impact on Your Child's Curriculum \& Future, Univariety, August 3, 2020.

[12] Ralhan, B. D. 'Challenges in implementing the National Education Policy 2020', Entrepreneur India. October 16, 2020.

[13] Singh, B. Opinion: The language conundrum of National Education Policy 2020, ET Government, Economic Times, October 9, 2020. 